\title{
Metabolismo oxidativo dos neutrófilos de ovinos tratados com monensina sódica e experimentalmente submetidos à acidose ruminal ${ }^{1}$
}

\author{
José Augusto B. Afonso ${ }^{2}$, Paulo C. Ciarlini ${ }^{3}$, Márcio R.G. Kuchembuck ${ }^{4}$, Aguemi \\ Kohayagawa $^{3}$, Lúcia P.Z. Feltrin ${ }^{3}$, Luciana D.R. Pinoti Ciarlini ${ }^{2}$, Cecília B. Laposy ${ }^{5}$, \\ Carla L. Mendonça ${ }^{2}$ e Regina K. Takahira ${ }^{3}$
}

\begin{abstract}
Afonso J.A.B., Ciarlini P.C., Kuchembuck M.R.G., Kohayagawa A., Feltrin L.P.Z., Ciarlini L.D.R.P., Laposy C.B., Mendonça C.L. \& Takahira R.K. 2002. [Oxidative metabolism of the neutrophils in sheep treated with sodium monensin and experimentally submitted to ruminal acidosis.] Metabolismo oxidativo dos neutrófilos de ovinos tratados com monensina sódica e experimentalmente submetidos à acidose ruminal. Pesquisa Veterinária Brasileira 22(4):129134. Clinica de Bovinos, UFRPE, Cx. Postal 152, Garanhuns, PE 55292-901, Brazil.

Ruminal acidosis is due to excessive ingestion of carbohydrates of rapid fermentation without previous adaptation of the microorganisms, causing severe metabolic disturbances to the animals. The objective of the present study was to assess the neutrophilic oxidative metabolism in sheep treated with sodium monensin in experimentally induced ruminal lactic acidosis. A total of 18 male sheep, half-bred (Ideal x Merino), fistulated in the rumen, were used; nine of them received $33 \mathrm{mg} / \mathrm{kg}$ of the ionophore diet per day, for 30 days; the others were controls. The acidosis was induced by supplying $15 \mathrm{~g}$ of sucrose $/ \mathrm{kg}$ of body weight. The clinical evaluation and the rumen and blood samples were obtained before (0h) and at 6,12 , 24 and 48 hours post-induction. In both groups, all the animals presented clinical manifestations of ruminal lactic acidosis 6 hours after the induction. From this period on, a significant pH decrease $(P<0.05)$ was observed in the ruminal fluid, which reached levels below 5 . There were relevant differences $(\mathrm{P}<0.05)$ between the groups 12 hours after the induction, when the sheep treated with monensin had higher values than those of the control group. During this period, the oxidative metabolism of the neutrophils remained inhibited, and the reestablishment of this function only occurred in the sheep which received monensin. Blood $\mathrm{pH}$, plasmatic glucose and the ionizable calcium suffered alterations within its levels. The seric cortisol concentration rose significantly $(\mathrm{P}<0.05)$ in both groups, although differences $(\mathrm{P}<0.05)$ between them were found at the end of the observation period. The treatment with monensin did not influence the oxidative metabolism of the neutrophils inhibited by the lactic acidosis; however, a faster recovery of this metabolism was verified in the animals treated with the ionophore.
\end{abstract}

INDEX TERMS: Ruminal acidosis, ionophores, sheep.

\footnotetext{
${ }^{1}$ Aceito para publicação em 12 de agosto de 2002.

${ }^{2}$ Clínica de Bovinos, Campus Garanhuns, Universidade Federal Rural de Pernambuco, Av. Bom Pastor s/n, Cx. Postal 152, Garanhuns, PE 55292-901.

${ }^{3}$ Depto Clínica, Cirurgia e Reprodução Animal, FMVA, Unesp, Campus Araçatuba, Araçatuba, SP 16015-050.

${ }^{4}$ Depto Clínica Veterinária, FMVZ, Unesp, Campus de Botucatu, Cx. Postal 560, Botucatu, SP 18618-000.

${ }^{5}$ Faculdade de Medicina Veterinária, UNOESTE, Presidente Prudente, SP 19050-680.
}

RESUMO.- A acidose láctica ruminal é causada pela ingestão excessiva de carboidratos de fermentação rápida sem uma prévia adaptação dos mocroorganismos, podendo com isso gerar distúrbios metabólicos graves aos ruminantes. Este trabalho tem por objetivo estudar o metabolismo oxidativo dos neutrófilos em ovinos tratados com a monensina sódica na acidose láctica ruminal induzida experimentalmente. Foram empregados 18 ovinos, machos, mestiços (Ideal x Merino), fistulados no rúmen; dos quais nove receberam $33 \mathrm{mg} / \mathrm{kg}$ da 
dieta do ionóforo ao dia, durante 30 dias, os demais ovinos pertenceram ao grupo controle. A acidose foi induzida fornecendo $15 \mathrm{~g}$ de sacarose $/ \mathrm{kg}$ de peso corporal. A avaliação clínica e as amostras de rúmen e sanguíneas foram obtidas antes (momento controle) $0 \mathrm{~h}$ e às $6 \mathrm{~h}, 12 \mathrm{~h}, 24 \mathrm{~h}$ e $48 \mathrm{~h}$ pósindução. Em ambos os grupos os animais apresentaram manifestações clínicas de acidose láctica ruminal 6 horas pósindução. A partir deste período se observou uma diminuição significativa $(\mathrm{p}<0,05)$ do $\mathrm{pH}$ no fluido ruminal, que alcançou valores inferiores a cinco, e diferenças significativas $(p<0,05)$ entre os grupos a partir das $12 \mathrm{~h}$ pós-indução foram constatadas, nos quais os ovinos tratados com a monensina apresentaram valores superiores em relação aos do grupo controle. Durante este período ocorreu uma inibição do metabolismo oxidativo dos neutrófilos nos animais estudados, ocorrendo restabelecimento desta função somente nos ovinos que receberam a monensina. $\mathrm{O} \mathrm{pH}$ sangüíneo, a glicose plasmática e o cálcio ionizável sofreram alterações nos seus índices. A concentração do cortisol sérico elevou-se de forma significativa $(p<0,05)$ em ambos os grupos, porém diferenças $(p<$ 0,05 ) entre eles foram constatadas ao final no período de observação. $O$ tratamento com a monensina não influenciou o metabolismo oxidativo dos neutrófilos, inibido pela acidose láctica; porém se verificou uma recuperação mais rápida deste metabolismo nos animais em que receberam o ionóforo.

TERMOS DE INDEXAÇÃO: Acidose ruminal, ionóforos, ovinos.

Classificação CNPq: 5.05.03.00-6 Patologia Animal.

\section{INTRODUÇÃO}

Os neutrófilos quando estimulados, manifestam um aumento do consumo de oxigênio denominado de "explosão respiratória", que gera uma grande quantidade de superóxido e peróxido de hidrogênio, dos quais derivam vários metabólitos oxidantes (Babior 1978). Os produtos oxidantes gerados pela "explosão respiratória" são de extrema importância para a função bactericida dos neutrófilos (Zinkl \& Kabbur 1997). Estudos em bovinos demonstraram que a deficiência do metabolismo oxidativo dos neutrófilos tornou os indivíduos mais susceptíveis à infecções (Kherli et al. 1989, Gilbert et al. 1993).

Nos neutrófilos o sistema NADPH oxidase catalisa a redução da molécula de oxigênio em ânion superóxido, de modo que esta reação é dependente de uma contínua redução de NADP em NADPH que é gerada às custas de um marcante aumento da glicólise pela via das pentoses (Babior 1978).

A acidose láctica ruminal é um dos principais distúrbios fermentativos que acomete os ruminantes. Após a ingestão abrupta, sem prévia adaptação, de quantidades elevadas de carboidratos facilmente fermentáveis contidos na alimentação, são produzidas alterações no rúmen, um quadro de acidose metabólica e vários processos secundários, que são potencialmente fatais. O fenômeno tem início com a elevada multiplicação, no rúmen, das duas principais bactérias Gram-positivas produtoras de ácido láctico, Streptococcus bovis e Lactobacillus sp (Nocek 1997, Owens et al. 1998).

Os antibióticos ionóforos são úteis no controle da acidose ruminal, pois deprimem ou inibem os microrganismos Gram- positivos que são produtores primários de ácido láctico, sem impedir a utilização deste por bactérias Gram-negativas como Megasphaera elsdenii e Selenomonas ruminantium (Nagaraja \& Taylor 1987). Trabalhos realizados por Nagaraja et al. (1981), Nagaraja et al. (1985), Ahuja et al. (1990), Bauer et al. (1995) e Afonso et al. (2000) observaram a eficiência do uso da monensina sódica, da lasalocida e de outros compostos do grupo dos ionóforos na prevenção da acidose láctica em bovinos, bubalinos e ovinos, nos quais verificaram que o $\mathrm{pH}$ do líquido ruminal manteve-se elevado e a concentração do ácido láctico baixa, concluindo que o emprego de ionóforos em dietas ricas em carboidratos nãoestruturais pode minimizar substancialmente as manifestações clínicas e subclínicas deste distúrbio digestivo.

Baseado na observação de que o ionóforo A23187 promove no neutrófilo, na presença de cálcio ionizado $\left(\mathrm{Ca}^{2+}\right)$, um acentuado consumo de oxigênio e uma maior produção de superóxido (Romeo et al. 1975), acredita-se que o aumento da concentração intracelular deste íon promova a ativação do metabolismo oxidativo (Penfield \& Dale 1984). Segundo Lew et al. (1984) e Higuchi et al. (1996), o $\mathrm{Ca}^{2+}$ intracelular é um segundo mensageiro muito importante para as diferentes funções dos neutrófilos de bovinos.

Estudos realizados em bovinos demonstraram que a administração de ionóforos como a monensina sódica aumenta a concentração de glicose plasmática e promove a função quimiotática dos neutrófilos (Abe et al. 1994, Stephenson et al. 1996).

Nós hipotetizamos que os distúrbios relacionados com a acidose láctica ruminal em ovinos podem alterar o metabolismo oxidativo dos neutrófilos, e que o tratamento destes com monensina pode contribuir para minimizar os efeitos negativos da acidose metabólica sobre esta função do neutrófilo. Objetivando testar tais hipóteses, procurou-se determinar as relações entre o metabolismo oxidativo dos neutrófilos com as alterações dos níveis de cálcio ionizado, glicose plasmática, cortisol sérico e pH ruminal e sangüíneo em ovinos com acidose láctica induzida experimentalmente, e submetidos ou não ao tratamento com a monensina sódica.

\section{MATERIAL E MÉTODOS}

Foram utilizados 18 ovinos machos, castrados, mestiços (Ideal $\mathrm{x}$ Merino) com peso entre 30 e $44 \mathrm{~kg}$, clinicamente sadios. Os animais foram submetidos ao implante cirúrgico de cânulas ruminais permanentes (Reichert Neto 1996). Durante toda a fase experimental, os ovinos receberam uma dieta, contendo $150 \mathrm{~g}$ de farelo de soja, administrado duas vezes ao dia por animal, além de feno de coastcross (Cynodon dactylon), sal mineral e água ad libitum.

Os ovinos foram subdivididos em dois grupos de nove animais; um grupo controle e o outro que recebeu a monensina sódica ${ }^{6}$ administrada diretamente no rúmen, através da fístula, na dose diária de $33 \mathrm{mg} / \mathrm{kg}$ da dieta, por animal, no decorrer de 30 dias (Rowe et al. 1981).

Após o período inicial de adaptação, a aplicação do antibiótico foi mantida e, a acidose foi induzida nos ovinos fornecendo como substrato $15 \mathrm{~g}$ de sacarose $/ \mathrm{kg}$ de peso corporal, através da fístula ruminal. As observações clínicas e as amostras do líquido ruminal e sanguíneas foram colhidas anteriormente (momento controle - $0 \mathrm{~h}$ )

\footnotetext{
${ }^{6}$ Rumensin 100, Elanco Saúde Animal, São Paulo, Brasil.
} 
Quadro 1. Valores das medianas de neutrófilos NBT-positivos, cortisol sérico e lactato rumenal, e médios do $\mathrm{pH}$ rumenal e sangüíneo, lactato plasmático, cálcio ionizado e glicose plasmática de ovinos tratados com monensina sódica e não tratados (controle). Resumo da análise estatística: comparações entre grupos em cada momento e entre momentos em cada grupo

\begin{tabular}{|c|c|c|c|c|c|c|}
\hline \multirow[t]{2}{*}{ Provas } & \multirow[t]{2}{*}{ Grupos } & \multicolumn{5}{|c|}{ Horas pós-indução } \\
\hline & & $0 \mathrm{~h}$ & $6 \mathrm{~h}$ & $12 \mathrm{~h}$ & $24 \mathrm{~h}$ & $48 \mathrm{~h}$ \\
\hline \multicolumn{7}{|c|}{ Neutrófilo NBT (+) } \\
\hline & Controle & $10^{\mathrm{Aa} *}$ & $5^{\text {Aa }}$ & $4^{\text {Aa }}$ & $3^{\text {Aa }}$ & $3^{\text {Aa }}$ \\
\hline & Monensina & $6^{\text {Aa }}$ & $3^{\text {Aa }}$ & $2^{\text {Aa }}$ & $2^{\text {Aa }}$ & $8^{\text {Aa }}$ \\
\hline \multicolumn{7}{|l|}{ pH Rumenal } \\
\hline & Controle & $6.39^{\mathrm{Aa}}$ & $4.79 \mathrm{Ab}$ & $4.33^{\mathrm{Ab}}$ & $4.31^{\mathrm{Ab}}$ & $5.70^{\text {Aab }}$ \\
\hline & Monensina & $6.57^{\text {Aac }}$ & $4.84^{\mathrm{Ab}}$ & $4.57^{\mathrm{Bb}}$ & $5.10^{\mathrm{Bbc}}$ & $6.74^{\mathrm{Bc}}$ \\
\hline \multicolumn{7}{|l|}{ pH Sangüíneo } \\
\hline & $\begin{array}{r}\text { Controle } \\
\text { Monensina }\end{array}$ & $\begin{array}{c}7.44^{\text {Aa }} \\
7.43^{\text {Aab }}\end{array}$ & $\begin{array}{l}7.44^{\text {Aa }} \\
7.44^{\text {Aa }}\end{array}$ & $\begin{array}{l}7.29 \mathrm{Ab} \\
7.32^{\mathrm{Ab}}\end{array}$ & $\begin{array}{l}7.36^{\mathrm{Aab}} \\
7.34^{\mathrm{Aab}}\end{array}$ & $\begin{array}{l}7.40^{\mathrm{Aab}} \\
7.38^{\mathrm{Aab}}\end{array}$ \\
\hline \multicolumn{7}{|c|}{ Ácido láctico rúmen (mg/dL) } \\
\hline & Controle & $0.13^{\text {Aab }}$ & $69.82^{\mathrm{Ab}}$ & $121.14^{\mathrm{Ac}}$ & $129.69^{\mathrm{Ac}}$ & $21.86^{\mathrm{Abc}}$ \\
\hline & Monensina & $0^{\text {Aa }}$ & $59.59^{\text {Aab }}$ & $117.24^{\mathrm{Ac}}$ & $31.76^{\mathrm{Bc}}$ & $0^{\mathrm{Ba}}$ \\
\hline \multicolumn{7}{|c|}{ Lactato plasmático (mmol/L) } \\
\hline & Controle & 0,71 Аa & $1,63^{\mathrm{Ab}}$ & $1,17^{\mathrm{Ab}}$ & $2,08^{\mathrm{Ab}}$ & $1,12^{\text {Aa }}$ \\
\hline & Monensina & $0,88^{\text {Aa }}$ & $1,78^{\mathrm{Ab}}$ & $1,12^{\text {Аа }}$ & $2,23^{\mathrm{Ab}}$ & 1,12 Аа \\
\hline \multicolumn{7}{|c|}{ Cálcio ionizável (mmol/L) } \\
\hline & Controle & $4.30^{\mathrm{Aa}}$ & $4.02 \mathrm{Ab}$ & 4.19 Аа & $3.79 \mathrm{Ab}$ & $3.65^{\mathrm{Ab}}$ \\
\hline & Monensina & 4.27 Аa & $3.97 \mathrm{Ab}$ & $4.23^{\text {Aa }}$ & $4.10^{\mathrm{Ab}}$ & $4.19^{\text {Аа }}$ \\
\hline \multicolumn{7}{|c|}{ Glicose plasmática (mg/dL) } \\
\hline & Controle & $62.44^{\mathrm{Aa}}$ & $100^{\mathrm{Ab}}$ & 59.44 Аа & 48.56 Аа & 53.89 Аа \\
\hline & Monensina & $63.56^{\text {Aa }}$ & $125.33^{\mathrm{Bb}}$ & 66.56 Аa & 64.89 Аа & $63.56^{\mathrm{Aa}}$ \\
\hline \multicolumn{7}{|c|}{ Cortisol sérico (mmol/L) } \\
\hline & Controle & 49.21 Aab & $61.36^{\mathrm{Ab}}$ & $173.26^{\mathrm{Ac}}$ & $64.03^{\mathrm{Abc}}$ & $137.13^{\text {Aabc }}$ \\
\hline & Monensina & 45.22 Аа & $81.80^{\mathrm{Aa}}$ & $126.17^{\mathrm{Ab}}$ & 86.87 Аа & 56.27 Ва \\
\hline
\end{tabular}

* Letras maiúsculas diferentes na mesma coluna indicam diferenças significativas $(p<0,05)$ entre grupos. Letras minúsculas diferentes na mesma linha indicam diferenças significativas $(p<0,05)$ entre momentos.

e nos intervalos de $6 \mathrm{~h}, 12 \mathrm{~h}, 24 \mathrm{~h}$, e $48 \mathrm{~h}$ pós-indução. O exame clínico foi realizado de acordo com Radostits et al. (2000).

A aferição do $\mathrm{pH}$ do líquido ruminal foi realizada um minuto após a colheita, utilizando-se um medidor de $\mathrm{pH}$, e o ácido láctico foi determinado por cromatografia gasosa ${ }^{7}$, segundo Erwin et al. (1961). $\mathrm{O}$ pH sanguíneo, a glicose e a concentração do cálcio ionizável foram realizadas em amostras de sangue obtidas por punção da veia jugular em seringas heparinizadas ${ }^{8}$ vedadas com tampa de borracha, refrigeradas, e analisadas em aparelho de hemogasometria $\mathrm{pH} / \mathrm{blood}$ $\mathrm{Gas}^{9}$, num intervalo de tempo de 10 minutos após a colheita. A determinação do lactato plasmático foi realizada enzimaticamente utilizando-se espectrofotômetro ${ }^{10}$, após colheita em fluoreto de sódio. 0 cortisol sérico foi determinado por radioimunoensaio (RIA) em fase sólida, utilizando-se reagente comercial ${ }^{11}$, empregando-se para contagem de radioatividade do teste um contador gama automático ${ }^{12}$.

O metabolismo oxidativo dos neutrófilos foi determinado estimando-se a produção de superóxido pelo teste citoquímico de redução espontânea do tetrazólio nitroazul (NBT), conforme descrito por Park \& Good (1970). Todos os testes de redução do NBT foram realizados $\operatorname{logo}$ em seguida a obtenção das amostras de sangue, utilizado-se tetrazólio nitroazul tamponado comercial ${ }^{13}$. 0 tempo de

${ }^{7}$ Cromatógrafo- modelo 370 - marca CG. São Paulo, Brasil.

${ }^{8}$ Liquemine : $5000 \mathrm{UI} / \mathrm{ml}$ de heparina., Rhodia, São Paulo, Brasil.

${ }^{9}$ Stat Profile 5 - Reagent Pack, Nova Biochemical, USA.

${ }^{10}$ Cobas Mira S, Roche - USA. reação foi de 10 minutos a $37^{\circ} \mathrm{C}$ e 10 minutos a temperatura ambiente. O percentual de células NBT positivas foi estimado a partir da contagem de 100 neutrófilos em esfregaços corados com Leishmann. Considerouse neutrófilo NBT-positivo, quando este apresentou qualquer grânulo intracitoplasmático de coloração azul a negro, independente do número e tamanho, desde que estes fossem claramente diferenciados das granulações tóxicas e corpúsculos de Döhle.

Conforme preconiza Siegel (1956), utilizou-se a prova de Mann Whitney para a comparação dos valores do teste de redução do NBT, dos níveis séricos de cortisol e ácido láctico do fluido ruminal entre grupos em cada momento e a prova de Friedman para comparação dos valores entre momentos em cada grupo. Para as comparações, entre grupos e momentos das variáveis glicose, cálcio ionizado, lactato plasmático, pH ruminal e sangüíneo, utilizou-se a análise de perfil para populações multinormais e homocedásticas, conforme Zar (1984).

\section{RESULTADOS E DISCUSSÃO}

Os dados obtidos do pH ruminal e sangüíneo, do ácido láctico ruminal e lactato plasmáticos, revelaram que a manifestação clínica mais intensa da acidose láctica ocorreu entre $12 \mathrm{~h}$ e

\footnotetext{
${ }^{11}$ Coat-a-Count- Cortisol, Diagnostic Products Co., Los Angeles, CA, USA.

${ }^{12}$ Kinecti Count 48, Vitek Systems, Missouri, USA.

${ }^{13}$ NBT vial, catalog No. 840-10, Sigma Diagnostic, St.Louis, USA.
} 
24h pós-indução e, em seguida, houve uma tendência ao restabelecimento desses valores, principalmente nos animais que receberam o ionóforo, alcançando valores próximos aos da pré-acidose 48 h pós-indução (Quadro 1). Embora a acidose ruminal tenha acometido, com a mesma intensidade, ambos os grupos, o pH ruminal do grupo tratado com monensina foi significativamente $(\mathrm{p}<0,05)$ superior ao do grupo controle a partir das $12 \mathrm{~h}$ pós-indução (Quadro 1). Tal alteração coincide com a diminuição na concentração do ácido láctico no fluido ruminal dos ovinos que receberam o antibiótico, a partir das 24h pós-indução, nos quais os valores foram inferiores de forma significativa $(p<0,05)$, quando comparado ao grupo controle. Acreditamos que devido à característica inibitória que tem este ionóforo sobre a microbiota Gram-positiva, principal produtora do ácido láctico e conseqüente responsável pela diminuição do $\mathrm{pH}$, tenha contribuído para este resultado favorável (Chen $\&$ Wolin 1979, Dennis et al. 1981).

Não ocorreu diferença estatística significativa $(p>0,05)$ nos valores de neutrófilos positivos, na prova de redução do NBT, determinados em ambos os grupos, e nem entre os respectivos momentos de cada um dos grupos; entretanto, em

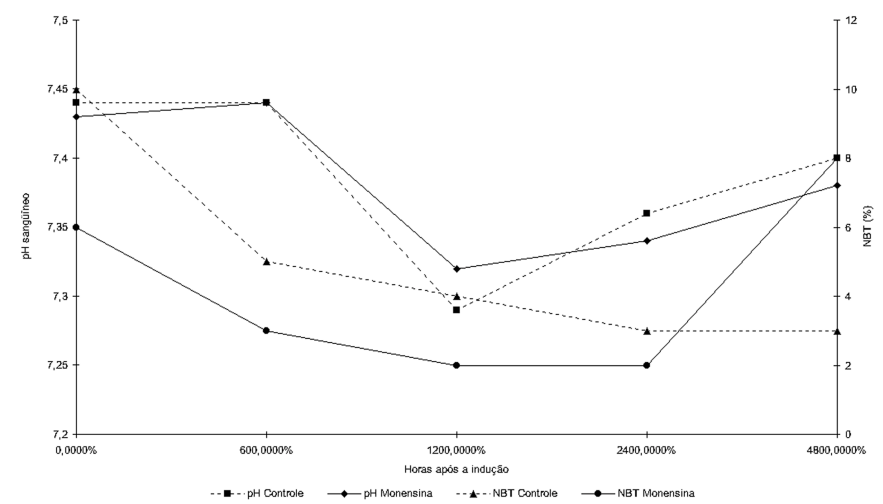

Fig. 1. Valores médios do pH sangüíneo e de mediana do NBT de ovinos tratados com monensina sódica e não tratados, na acidose ruminal experimental.

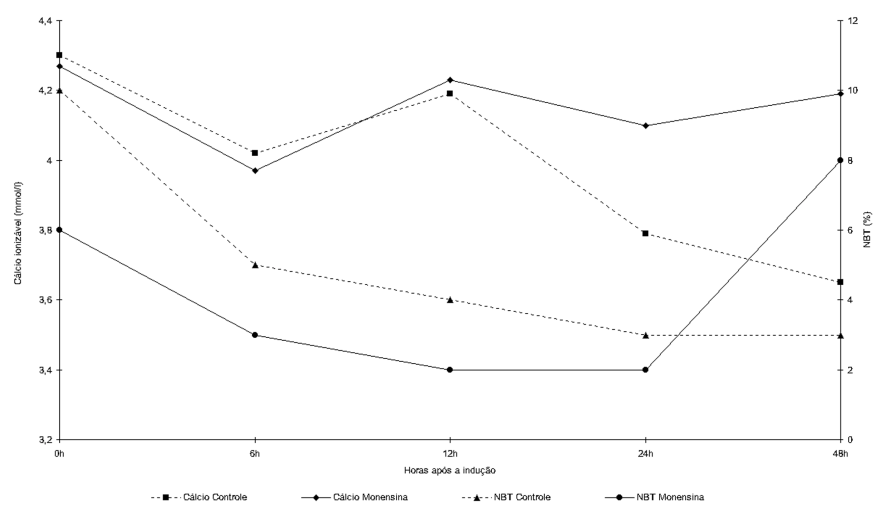

Fig. 2. Valores de mediana do cálcio ionizável e do NBT de ovinos tratados com monensina sódica e não tratados, na acidose ruminal experimental. ambos os grupos ocorreu uma diminuição de aproximadamente $50 \%$ de neutrófilos NBT-positivos 6 horas após a indução da acidose, assim que a recuperação dos valores do $\mathrm{pH}$ ruminal e sanguííneo não implicou no restabelecimento da capacidade dos neutrófilos do grupo controle reduzirem o NBT (Quadro 1, Fig. 1). Diferentemente do grupo controle, os animais do grupo da monensina apresentaram, $48 \mathrm{~h}$ pós-indução, valores de neutrófilos NBT-positivos próximos aos observados no momento controle (0h), indicando um possível restabelecimento do metabolismo oxidativo desses granulócitos. Os dados obtidos sugerem que outros fatores associados à acidose ruminal, que não a diminuição do $\mathrm{pH}$ sangüíneo, possa afetar o metabolismo oxidativo dos neutrófilos.

A diminuição dos valores de neutrófilos NBT-positivos foi coincidente com o decréscimo do $\mathrm{Ca}^{2+}$ ionizável (Fig. 2). Em ambos os grupos, os valores para o $\mathrm{Ca}^{2+}$ plasmático $6 \mathrm{~h}$ pósindução foi significativamente $(p<0,05)$ inferior ao observado no momento controle (0h) (Quadro 1). Alguns estudos demonstraram que o aumento de $\mathrm{Ca}^{2+}$ intracelular é essencial para ativação de vários mecanismos dos neutrófilos, inclusive o metabolismo oxidativo (Lew et al. 1984, Penfield \& Dale 1984, Higuchi et al. 1996). No entanto, Dewald \& Baggiolini (1985) verificaram que o metabolismo oxidativo do neutrófilo depende também da concentração de $\mathrm{Ca}^{2+}$ extracelular. Todavia, nossas observações contrariam esta hipótese, uma vez que a elevação do $\mathrm{Ca}^{2+}$ sanguiíneo verificada $12 \mathrm{~h}$ pós-indução, em ambos os grupos, não restabeleceu o metabolismo oxidativo dos neutrófilos, sugerindo que outros fatores devem contribuir para a inibição deste metabolismo nesta fase da acidose. Kehrli \& Goff (1989) verificaram que durante o pré-parto, as vacas hipocalcêmicas restabeleceram a normocalcemia após o tratamento com paratormônio, entretanto, este fato não implicou no restabelecimento do metabolismo oxidativo dos neutrófilos. Segundo estes autores, o $\mathrm{Ca}^{2+}$ utilizado para a ativação dos neutrófilos deriva de compartimentos intracelulares, e esta pode ocorrer na ausência de $\mathrm{Ca}^{2+}$ extracelular, embora a fonte de $\mathrm{Ca}^{2+}$ extracelular provavelmente seja importante para

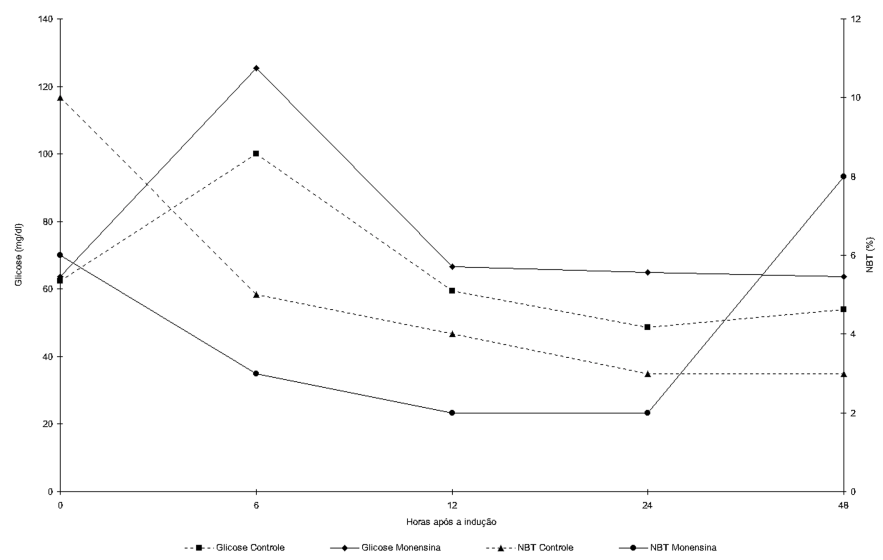

Fig. 3. Valores médios da glicose plasmática e de mediana do NBT de ovinos tratados com monensina sódica e não tratados, na acidose ruminal experimental. 


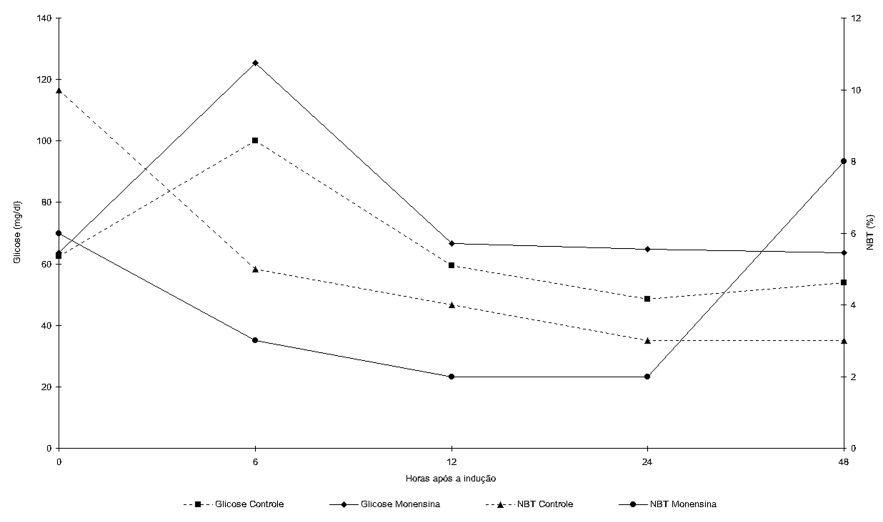

Fig. 4. Valores de mediana do cortisol sérico e do NBT de ovinos tratados com monensina sódica e não tratados, na acidose ruminal experimental.

manter a ativação destes granulócitos. Portanto, deve-se considerar a possibilidade de que a diminuição do $\mathrm{Ca}^{2+}$ sangǘneo causada pela acidose ruminal não tenha sido o principal fator inibidor do metabolismo oxidativo dos neutrófilos no presente estudo.

Em ambos os grupos, as concentrações de glicose plasmática $6 \mathrm{~h}$ pós-indução da acidose foram significativamente $(\mathrm{p}<0,05)$ superiores aos dos demais momentos. Os valores glicêmicos dos animais tratados com monensina apenas foram significativamente $(\mathrm{p}<0,05)$ superiores aos do grupo controle 6h PI. A diminuição da função oxidativa dos neutrófilos durante a acidose (Fig. 3) não deveu-se a uma restrição energética, assim como a recuperação mais rápida desse metabolismo oxidativo nos animais do grupo monensina não ocorreu devido a um aumento da glicemia. Stephewson et al.(1996) observaram que a atividade quimiotática de neutrófilos de bovinos tratados com monensina foi superior aos do grupo não tratado. Não foi verificada diferença nos valores da glicose sanguínea de animais tratados e não tratados com a monensina, e concluíram que este ionóforo compromete a função dos neutrófilos independentemente da glicemia, alterando o fluxo metabólico energético, modificando o metabolismo mineral, aumentando a absorção de cátions bivalentes, incluindo o cobre e o selênio, pois altera a bomba $\mathrm{Na} / \mathrm{K}$ ATPase ou por outro mecanismo ainda não determinado.

Neste estudo, a concentração sérica de cortisol aumentou acentuadamente, alcançando valores máximos $12 \mathrm{~h}$ pósindução da acidose em ambos os grupos (Fig. 4). Os índices do cortisol no grupo dos ovinos, que receberam a monensina retornaram aos valores pré-estabelecidos $48 \mathrm{~h}$ pós-indução; porém, este achado não foi observado no grupo controle, nos quais os animais apresentaram a concentração desta variável significativamente $(\mathrm{p}<0,05)$ superiores. É reconhecido que a elevação dos níveis de cortisol causa in vivo a inibição do metabolismo oxidativo dos neutrófilos (Roth et al. 1982). Portanto, é bastante provável que o aumento de neutrófilos NBT-positivos no grupo monensina após $48 \mathrm{~h}$ da indução da acidose esteja relacionada à diminuição do estresse, fato este não observado no grupo controle. Estes resultados demonstraram, claramente, que os animais tratados com monensina sódica se recuperaram mais rapidamente da acidose láctica, sendo submetidos a um menor estresse, de modo que o metabolismo oxidativo dos neutrófilos desses animais ficaram inibidos por um intervalo de tempo menor.

Pode-se concluir que o tratamento com a monensina não impediu que o metabolismo oxidativo dos neutrófilos fosse inibido pela acidose láctica ruminal; no entanto, verificou-se uma recuperação mais rápida desta característica nos animais que receberam o ionóforo, quando comparado aos animais do grupo controle, tornando-os, provavelmente, menos susceptíveis a processos infecciosos.

Agradecimentos.- À Fundação de Amparo à Pesquisa do Estado de São Paulo (FAPESP), pelo apoio financeiro.

\section{REFERÊNCIAS}

Abe N., Lean I.J., Rabiee A., Porter J. \& Graham C. 1994. Effects of sodium monensin on reproductive performance of dairy cattle. II Effects on metabolites in plasma, resumption of ovarian cyclicity and oestrus in lactating cows. Aust. Vet. J. 71:277-282.

Afonso J.A.B., Kuchembuck M.R.G., Feltrin L.P.Z., Laposy C.B., Kohayagawa A., Mendonça C.L. \& Takahira R.K. 2000. Avaliação clínica do uso da monensina sódica na prevenção da acidose láctica ruminal em ovinos. In: XXVII Congr. Bras. Med. Vet., Águas de Lindóia, SP, p. 26.

Ahuja A.K., Randhawa S.S. \& Rathor S.S. 1990. Effect of monensin in ameliorating subacute lactic acidosis in buffalo calves. Acta Vet. BRNO 59:171-178.

Babior B.M. 1978. Oxigen-dependent microbial killing by phagocytes. N. Engl. J. Med. 298:659-668.

Bauer M.L., Herold D.W., Britton R.A., Klopfenstein T.J. \& Yates D.A. 1995. Efficacy of laidlomycin propionate to reduce ruminal acidosis in cattle. $\mathrm{J}$. Anim. Sci. 73:3445-3454.

Chen M. \& Wolin M.J. 1979. Effect of monensin and lasalocid-sodium on the growth of methanogenic and rumen saccharolytic bacteria. Appl. Environ. Microbiol. 38:72-77.

Dennis S.M., Nagaraja T.G. \& Bartley E.E. 1981. Effect of lasalocid or monensin on lactate-producing or using rumen bacteria. J. Anim. Sci. 52:418-426.

Dewald B. \& Baggiolini M. 1985. Activation of NADPH oxidase in human neutrophils. Synergism between FMLP and the neutrophil products PAF and $\mathrm{LTB}_{4}$. Biochem. and Biophy. Res. Commun. 128:297-304.

Erwin E.S., Marco G.J. \& Emery E.M. 1961. Volatile fatty acid analyses of blood and rumen fluid by gas chromatography. J. Dairy Sci. 44:1768-1771.

Gilbert R.O., Gröhn Y.T. \& Miller P.M. 1993. Effect of parity on periparturient neutrophil function in dairy cows. Vet. Immunol. Immunopathol. 36:75-82.

Higuchi H., Nagahata H., Hiroki M. \& Noda H. 1997. Relationship between Age-Dependent changes of bovine neutrophil function and their intracellular $\mathrm{Ca}^{2+}$ concentrations. J. Vet. Med. Sci. 59:271-276.

Kehrli M.E. \& Goff J.P. 1989. Periparturient hypocalcemia in cows: effects on peripheral blood neutrophil and lymphocyte function. J. Dairy Sci. 72:11881196.

Kehrli M.E., Nonnecker B.J. \& Roth J.A. 1989. Alterations in bovine neutrophil function during the periparturient period. Am. J. Vet. Res. 50:207-214.

Lew D.P., Wollweim C.B., Waldvogel F.A. \& Pozzan T. 1984. Modulation of cytosolic-free $\mathrm{Ca}^{2+}$ transients by changes in intracellular calcium-buffering capacity: correlation with exocytosis and $\mathrm{O}_{2}$ - production in human neutrophil. J. Cell Biol. 112:1249-1257.

Nagaraja T.G. \& Taylor M.B. 1987. Susceptibility and resistance of ruminal bacteria to antimicrobial feed aditives. Appl. Environ. Microbiol. 53:1620-1625. 
Nagaraja T.J., Avery T.B., Galitzer S.J. \& Harmond D.L. 1985. Effect of ionophore antibiotics on experimentally induced lactic acidosis in cattle. Am. J. Vet. Res. 46:2444-2452.

Nagaraja T.G., Avery T.B., Bartley E.E. \& Galitzer, S.J. 1981. Prevention of lactic acidosis in cattle by lasalocid or monensin. J. Anim. Sci. 53:206-216.

Nocek J.E. 1997. Bovine acidosis: implication on laminitis. J. Dairy Sci. 80:10051028.

Owens F.N., Secrist D.S., Hill W.J. \& Gill D.R. 1998. Acidosis in cattle: a review. J. Anim. Sci. 76:275-286.

Park B.H. \& Good R.A. 1970. N.B.T test stimulated. Lancet 19:616.

Penfield A. \& Dale M.M. 1984. Synergism between A23187 and 1-oleoyl-2acetyl-glycerol in superoxide production by human neutrophils. Biochem. Biophys. Res. Commun. 125:332-336.

Radostits O.M., Gay C.C., Blood D.C. \& Hinchdliff K.W. 2000. Veterinary Medicine. 9th ed. W.B. Saunders, London, 1877p.

Reichert Neto N.C. 1996. Fistulação ruminal em ovinos. In: XV Congr. Panam. Ciências Vet., p.127. (Resumo)

Romeo D., Zabucchi G., Miani N. \& Rossi F. 1975. Ion movement across leukocyte plasma membrane and excitation of their metabolism. Nature 253:542-544.

Roth J. A., Kaerberle M.L. \& Hsu W.H. 1982. Effects of ACTH administration on bovine polymorphonuclear leukocyte function and lymphocyte blastogenesis. Am. J. Vet. Res. 43:412-416.

Rowe J.B., Davies A. \& Broome A.W.J. 1981. Quantitative changes in the rumen fermentation of sheep, associated with feeding monensin. Proc. Nutr. Soc. 41:3A.

Siegel S. 1956. Non Parametrics Statistics for the Behavioral Sciences. MacGraw-Hill, New York. 312p.

Stephenson K.A., Lean I.J. \& O'meara T.J. 1996. The effect of monensin on the chemotactic function of bovine neutrophils. Aust. Vet. J. 74:315317.

Zar J.H. 1984. Bioestatistical Analysis. 2nd ed. Prentice Hall, Englewood Cliffs. $718 \mathrm{p}$.

Zinkl J.G. \& Kabbur M.B. 1997. Neutrophil function. In: Kaneko J.J., Harvey J.W. \& Bruss, M.L (ed.) Clinical Biochemistry of Domestic Animals. 5th ed. Academic Press, San Diego, p.285-302. 